Jurnal Abdidas Volume 2 Nomor 6 Tahun 2021 Halaman 1269 - 1275

JURNAL ABDIDAS

http://abdidas.org/index.php/abdidas

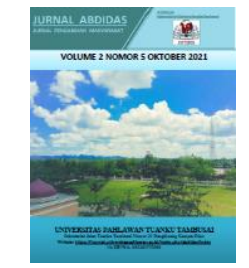

\title{
Sosialisasi Pentingnya Kartu Kunjungan Berobat Pasien di Puskesmas Ulak Karang Padang
}

\author{
Dewi Mardiawati ${ }^{1}$, Berly Nisa Srimayarti ${ }^{2}$, Linda Handayuni ${ }^{3}$, Dian Sari ${ }^{4}$, Hendra Nusa Putra ${ }^{5}$, Annisa \\ Septina Fariza ${ }^{6}$, Annisa Zakia ${ }^{7}$, Aqia Defira Dinda ${ }^{8}$ \\ DIII Rekam Medis dan Informasi Kesehatan, STIKES Dharma Landbouw, Indonesia ${ }^{1,3,4,5,6,7,8}$ \\ Administrasi Rumah Sakit, STIKES Dharma Landbouw, Indonesia, ${ }^{2}$ \\ E-mail : dmardiawati@gmail.com ${ }^{1}$, berlynisasrimayarti@gmail.com ${ }^{2}, \underline{\text { lindahandayuni @ gmail.com }}^{3}$, \\ dian_sari83@yahoo.co.id ${ }^{4}$, nusahendra@gmail.com ${ }^{5}$, annisaseptinaf@gmail.com ${ }^{6}$, annisazakia@ gmail.com ${ }^{7}$, \\ aqiadefirad@gmail.com ${ }^{8}$
}

\begin{abstract}
Abstrak
Kartu Kunjungan Berobat pasien merupakan identitas atau pengenal pasien pada saat berobat ke tempat layanan kesehatan. Puskesmas Ulak Karang menerapkan family numbering diketahui dimana kartu kunjungan berobat pasien digunakan oleh semua anggota keluarga sehingga dapat memperlama waktu pelayanan pendaftaran pasien, Ini terjadi jika pasien tidak membawa kartu kunjungan berobat, selain itu kondisi nya yang rusak dan tulisannya yang luntur sehingga menyulitkan proses identifikasi. Tujuan pengabdian kepada masyarakat adalah bagaimana pentingnya membawa kartu kunjungan berobat agar pelayanan menjadi lebih bermutu. Pengabdian ini dilakukan di Puskesmas Ulak Karang Padang dimana yang menjadi audien adalah pasien yang datang berkunjung di waktu kami melakukan sosialisasi di puskesmas tersebut. Sosialisasi disampaikan melalui ceramah dengan batuan media audio visual, sehingga materi bisa di sampaikan dengan baik. Hasil kegiatan menunjukkan bahwa sosialisasi berjalan dengan lancar dan diharapkan peserta dapat menerima materi yang diberikan serta aktif dan bersemangat dalam penyuluhan. Kegiatan soasilisasi pentingnya kartu kunjungan/kartu identitas berobat merupakan indikator mutu pada pelayanan kesehatan.
\end{abstract}

Kata kunci: kartu kunjungan, kartu berobat, pasien

\begin{abstract}
The patient's medical visit card is the identity or identification of the patient at the time of treatment at a health service place. The Ulak Karang Health Center applies family numbering, it is known that the patient's medical visit card is used by all family members so that it can prolong the patient registration service time. The purpose of community service is how important it is to bring a medical visit card so that the service becomes more quality. This service was carried out at the Ulak Karang Padang Health Center where the audience was the patients who came to visit when we did the socialization at the puskesmas. The socialization was delivered through lectures using audio-visual media, so that the material could be conveyed properly. The results of the activity showed that the socialization went smoothly and it was hoped that participants could accept the material provided and be active and enthusiastic in counseling. Socialization activities on the importance of visiting cards/medical identity cards are indicators of quality in health services.
\end{abstract}

Keywords: visiting card, medical card, patient

Copyright (c) 2021 Dewi Mardiawati, Berly Nisa Srimayarti, Linda Handayuni, Dian Sari, Hendra Nusa Putra, Annisa Septina Fariza, Annisa Zakia, Aqia Defira Dinda

$\triangle$ Corresponding author : Dewi Mardiawati

Address : : STIKES Dharma Landbouw Padang

Email : : dmardiawati@gmail.com

DOI $\quad:$ https://doi.org/10.31004/abdidas.v2i6.345

ISSN 2721-9224 (Media Cetak)

ISSN 2721- 9216 (Media Online) 
1270 Sosialisasi Pentingnya Kartu Kunjungan Berobat Pasien di Puskesmas Ulak Karang Padang - Dewi Mardiawati, Berly Nisa Srimayarti, Linda Handayuni, Dian Sari, Hendra Nusa Putra, Annisa Septina Fariza, Annisa Zakia, Aqia Defira Dinda

DOI: https://doi.org/10.31004/abdidas.v2i6.345

\section{PENDAHULUAN}

Menurut kamus Bahasa Indonesia, mutu adalah ukuran, derajat, atau taraf tentang baik buruknya suatu produk barang atau jasa. Mutu adalah perpaduan sifat-sifat dan karakteristik produk atau jasa yang dapat memenuhi kebutuhan pemakai atau pelanggan (Bustami, 2011). Menurut A.A. Gde Muninjaya (2011), mutu adalah apa yang diharapkan atau ditentukan oleh konsumen. Mutu pada pelayanan kesehatan harus juga dilaksanakan pada Puskesmas.

Puskesmas adalah fasilitas pelayanan kesehatan tingkat pertama yang menyediakan pelayanan kepada masyarakat. Oleh karena itu perlu ditetapkan jenis-jenis pelayanan yang disediakan bagi masyarakat sesuai dengan kebutuhan masyarakat dan permasalahan kesehatan yang ada di wilayah kerjanya dengan mendapatkan masukan dari masyarakat melalui proses pemberdayaan masyarakat (Permenkes RI, 2014).

Salah satu bentuk pelayanan di Puskesmas meliputi pelayanan medis dan penunjang, salah satu dari pelayanan penunjang dalam rangka pencapaian pembangunan kesehatan di Puskesmas adalah bagian rekam medis. Bagian rekam medis merupakan gerbang utama dalam pelayanan kesehatan, dan dapat dijadikan sebagai salah satu tingkat kepuasan pasien dalam menerima pelayanan kesehatan. Ruang lingkup bagian kerja rekam medis dimulai dari penerimaan pasien sampai dengan cara penyajian informasi kesehatan. Tugas bagian kerja rekam medis dimulai dari pengumpulan data, pemrosesan data, dan penyajian data informasi kesehatan (Budi, 2011).

Rekam medis merupakan suatu catatan baik tertulis maupun yang terekam, berisikan identitas pasien, anamnesa, pengobatan, diagnosis, tindakan serta pelayanan lainnnya yang diberikan oleh petugas kepada pasien baik pelayanan rawat jalan, rawat inap maupun gawat darurat (Departemen Kesehatan Republik Indonesia, 2006), (Kementerian Republik Indonesia, 2008), (Berly Nisa Srimayarti, 2019).

Kegiatan rekam medis pertama di Pelayanan Kesehatan pertama kali dilaksanakan dibagian Pendaftaran tidak terkecuali di Puskesmas. Salah satu penunjang lancarnya pelayanan di bagian Pendaftaran yaitu tersedianya Kartu Kunjungan Berobat khususnya pelayanan untuk pasien lama. Menurut Alifia (2010) jika pasien tidak membawa Kartu Kunjungan akan memperlama waktu penyediaan dokumen Rekam Medis (Harjani, 2020).

Kartu Kunjungan Berobat merupakan tanda pengenal yang harus dibawa setiap kali berobat sama baik rawat jalan maupun rawat inap dan difungsikan untuk melihat nomor rekam medis pasien (Departemen Kesehatan Republik Indonesia, 2006), (Sudra, 2013), (Devid Leonard, 2017).

Penerapan sistem penomoran di Puskesmas Ulak Karang Padang yaitu Family Numbering System dengan menggunakan kode wilayah dan indeks keluarga. Jadi walaupun menggunakan sistem keluarga namun pasien sebenarnya mendapatkan satu nomor yang berbeda antara satu 
1271 Sosialisasi Pentingnya Kartu Kunjungan Berobat Pasien di Puskesmas Ulak Karang Padang - Dewi Mardiawati, Berly Nisa Srimayarti, Linda Handayuni, Dian Sari, Hendra Nusa Putra, Annisa Septina Fariza, Annisa Zakia, Aqia Defira Dinda

DOI: https://doi.org/10.31004/abdidas.v2i6.345

keluarga dengan keluarga yang lain. Nomor pasien yang diberikan pada saat pertama kali berobat digunakan untuk berobat selanjutnya atau disebut sebagai Unit Numbering System (UNS) (Harjani, 2020).

Berdasarkan survei pendahuluan di Puskesmas Puskesmas Ulak Karang Utara Kota Padang yang menerapkan Family Numbering System diketahui bahwa kartu kunjungan berobat pasien digunakan oleh semua anggota keluarga. Hal ini memperlama waktu pelayanan pendaftaran jika pasien tidak membawa Kartu kunjungan Berobat. Alasan Kartu Kunjungan Berobat dibawa oleh pasien karena Kartu Kunjungan Berobat dibawa oleh anggota keluarga yang lain sehingga petugas harus mencari nomor rekam medis tersebut pada Sistem Manajemen Puskemas (SIMPUS) terlebih dahulu, baru bisa mencarikan Family Folder keluarga pasien tersebut untuk digunakan pemeriksaan. Jikapun pasien membawa Kartu Kunjungan Berobat sudah dalam kondisi robek ataupun tulisannya luntur sehingga menyulitkan proses identifikasi data pasien.

\section{METODE}

Pelaksanaan kegiatan sosialisasi kartu kunjungan berobat khususnya Kartu Kunjungan Berobat Pasien dilaksanakan pada tanggal 16 Juli 2020 Jalan S.Parman Ulak Karang Utara Padang Provinsi Sumatera Barat dengan jumlah peserta anak-anak sebanyak 35 orang.

Pendekatan yang dilakukan adalah promosi kesehatan berupa sosialisasi dan demonstrasi Pentingnya membawa Kartu Kunjungan
berobat/Kartu Identitas berobat di puskesmas dengan menggunakan beberapa strategi yang bersifat paripurna (komprehensif). Sosialisasi ini pada indikator yaitu Sosialisasi pentingnya membawa kartu kunjungan berobat. Sosialisasi ini dilakukan di Puskesmas Ulak Karang Kecamatan Ulak Karang. Sosialisasi ini dilakukan oleh 4 orang dosen dan dibantu oleh 3 orang mahasiswa. Sosialisasi diberikan dengan bentuk penyuluhan ini dilakukan kepada 35 peserta yaitu pasien yang datang berobat.

Sosialisasi dengan bentuk penyuluhan ini dilakukan dengan melalui 4 tahapan yaitu (1) survei kelompok sasaran, (2) persiapan sarana dan prasarana, (3) pelaksanaan kegiatan inti, dan (4) evaluasi. Survei kelompok sasaran bertujuan untuk mendapatkan informasi tentang lokasi dan tujuan yang belum pernah diadakan kegiatan yang serupa. Persiapan sarana dan prasarana meliputi pemilihan tempat edukasi dan demonstrasi yang tepat dan efektif dan persiapan alat-alat yang dibutuhkan seperti Infokus, laptop, Poster dan Leafleat.

Pada kegiatan ini, muatan program yang paling penting adalah memberikan sosialisasi dengan cara demonstrasi tentang pentingnya kartu kunjungan berobat. Sosialisasi dilakukan dengan metode ceramah, demonstrasi. Agar materi edukasi dan demontrasi tersampaikan dengan maksimal, maka digunakan media berupa leaflet berisi tentang pengertian, tujuan, alat dan bahan, dengan cara biasa presentasi makalah serta video demonstrasi terkait kegiatan pentingnya membawa kartu kunjungan berobat. Kegiatan 
1272 Sosialisasi Pentingnya Kartu Kunjungan Berobat Pasien di Puskesmas Ulak Karang Padang - Dewi Mardiawati, Berly Nisa Srimayarti, Linda Handayuni, Dian Sari, Hendra Nusa Putra, Annisa Septina Fariza, Annisa Zakia, Aqia Defira Dinda

DOI: https://doi.org/10.31004/abdidas.v2i6.345

terakhir yang dilakukan adalah evaluasi yang meliputi evaluasi struktur, proses dan hasil.

\section{HASIL DAN PEMBAHASAN}

Kartu identitas berobat disusun secara alphabet seperti susunan kata-kata dalam kamus, sehingga mempercepat dan mempermudah mengambilkan kartu indeks nama jika sewaktu waktu dibutuhkan. Penyimpanan kartu indeks harus diberi petunjuk maksimum hanya diletakkan 20 kartu saja, pengecekan terhadap kartu-kartu harus dilakukan secara periodic untuk memperbaiki kekeliruan yang mungkin terjadi.

\section{Tujuan Kegunaan Kartu Kunjungan Berobat}

Mempunyai kegunaan yang sangat penting baik bagi pasien sendiri maupun bagi sarana pelayanan kesehatan (rumah sakit, puskesmas dan klinik).

1. Bagi pasien, Kartu Identitas Berobat (KIB) berguna sebagai sebagai bukti bahwa pasien telah mendaftar dan tercatat sebagai pasien, yang dibawa setiap kali berobat pada instansi yang sama.

2. Bagi sarana pelayanan kesehatan adalah untuk memudahkan petugas pendaftaran di rumah sakit dalam mencari berkas rekam medis pasien lama. (Anton, 2018)

\section{Prosedur Membuat Kartu Berobat/Kartu}

\section{Kunjungan}

1. Persyaratan
a. Membawa Kartu Identitas/Kartu berobat Pasien
b. Membawa fotocopy KK/KTP
c. Membawa kartu BPJS/KIS bila memiliki

2. Sistem, Mekanisme dan Prosedur
a. Petugas mempersilahkan pasien mengambil nomor antrian

b. Petugas menyiapkan perlengkapan untuk pendaftaran pasien

c. Petugas memanggil pasien sesuai nomor urut

d. Petugas menanyakan apakah pasien baru atau lama

e. Apabila pasien baru petugas menulis identitas pasien secara lengkap

f. Petugas menulis Nama KK, Alamat, dan nomor Rekam Medis pada kartu tanda berobat

g. Petugas menjelaskan kepada pasien kalau kartu berobat itu dipakai untuk satu keluarga

h. Petugas menyerahkan kartu berobat kepada pasien

i. Petugas mengingatkan kepada pasien untuk selalu membawa kartu berobat itu kalau akan berkunjung ke Puskesmas

j. Petugas mengingatkan untuk menyimpan kartu berobat tersebut dan jangan sampai hilang

Pendekatan yang dilakukan adalah promosi kesehatan berupa sosialisasi pentingnya Kartu Kunjungan Berobat untuk Pasien dengan 
1273 Sosialisasi Pentingnya Kartu Kunjungan Berobat Pasien di Puskesmas Ulak Karang Padang - Dewi Mardiawati, Berly Nisa Srimayarti, Linda Handayuni, Dian Sari, Hendra Nusa Putra, Annisa Septina Fariza, Annisa Zakia, Aqia Defira Dinda

DOI: https://doi.org/10.31004/abdidas.v2i6.345

menggunakan beberapa strategi yang bersifat paripurna (komprehensif). Sosialisasi ini pada indikator yaitu Pentingnya Sosialisasi Kartu Kunjungan berobat pada pasien di Puskesamas Ulak Karang Padang dari kegiatan yang dilakukan. Kegiatan inti Sosialiasi ini dilakukan dengan 4 tahap yaitu : (1) Pra Interaksi, (2) Interaksi, (3) Demonstrasi, dan (4) Post interaksi.

Pengabdian masyarakat ini dilaksanakan pada pasien yang berobat, dengan jumlah yang mengikuti sosialisasi 35 orang. Berikut kegiatan pengabdian masyarakat dilaksanakan dengan beberapa tahapan, sebagai berikut:

1. Tahap Pra interaksi

Tahap ini melakukan pengurusan izin pelaksanaan dengan Puskesmas Ulak karang yang akan dilakukan Pengabmas.

2. Tahap Interaksi

Tahap ini kegiatan pengabmas melakukan koordinasi dengan pihak puskesmas bahwa kami akan melakukan pengabmas, dan tim pengabmas menyiapkan peralatan dan bahan untuk pelaksanaan sosialisasi edukasi tentang Kartu Kunjungan Berobat/kartu Identitas Berobat untuk meningkatkan Mutu pelayanan Kesehatan bagi Puskesmas dari kegiatan yang dilakukan.

3. Tahap Demontrasi

Tahap ini Kegiatan pengabdian dilakukan dalam bentuk sosialisasi kepada pasien yang datang ke Puskesmas terkait tentang Kartu Kunjungan Berobat. Bentuk sosialisasi yang dilakukan bersifat menambah pengetahuan pasien yang datang dengan cara menyampaikan informasi, pesan dan menumbuhkan keyakinan kepada responden, sehingga pasien yang datang ke Puskesmas bisa memahami dan tentang pentingnya kartu Kunjungan Berobat

Pengabdian masyarakat ini dilakukan dalam bentuk:

a. Memberikan Sosialisasi dengan cara demonstrasi tentang Kartu Kunjungan Berobat.

b. Sosialisasi atau dilakukan dengan metode ceramah, demonstrasi Kartu Kunjungan Berobat dan tanya jawab.

c. Materi sosailisasi tersampaikan dengan maksimal, maka digunakan media berupa leaflet berisi tentang pengertian, tujuan, alat dan bahan, dan pentingnya Kartu Kunjungan Berobat dengan cara penyampaian secara langsung dengan PPT dan memberikan brosur dan leaflet untuk melakukan sosialisasi.

d.

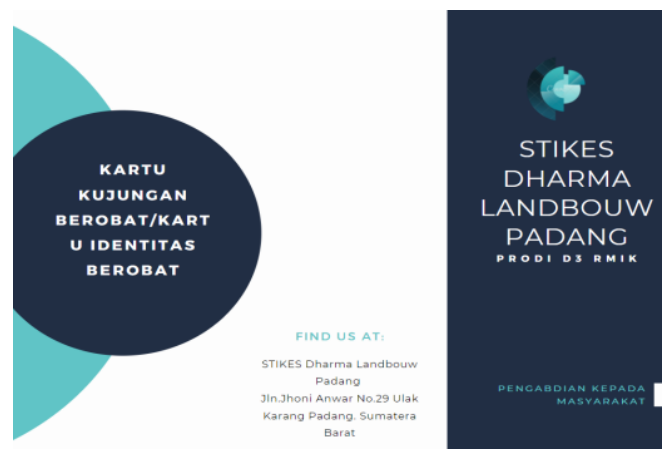

Gambar 1. Cover Brosur dan leaflet 
1274 Sosialisasi Pentingnya Kartu Kunjungan Berobat Pasien di Puskesmas Ulak Karang Padang - Dewi Mardiawati, Berly Nisa Srimayarti, Linda Handayuni, Dian Sari, Hendra Nusa Putra, Annisa Septina Fariza, Annisa Zakia, Aqia Defira Dinda

DOI: https://doi.org/10.31004/abdidas.v2i6.345
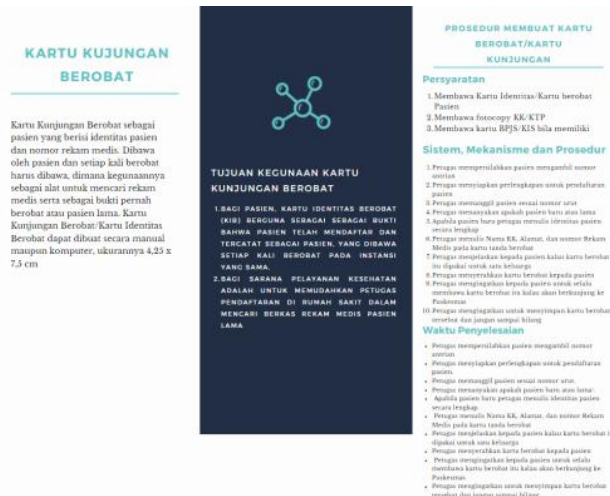

Gambar 2. Isi Brosur dan leaflet

Dalam Pelaksanaan Peserta tampak dengan serius mendengarkan penyampaian materi. Peserta tampak senang dan bersemangat mengikuti penyuluhan karena banyak terlihat peserta yang ikut sosialisasi terlihat aktif saat diajak pemateri maupun saat pemateri memberikan pertanyaan.

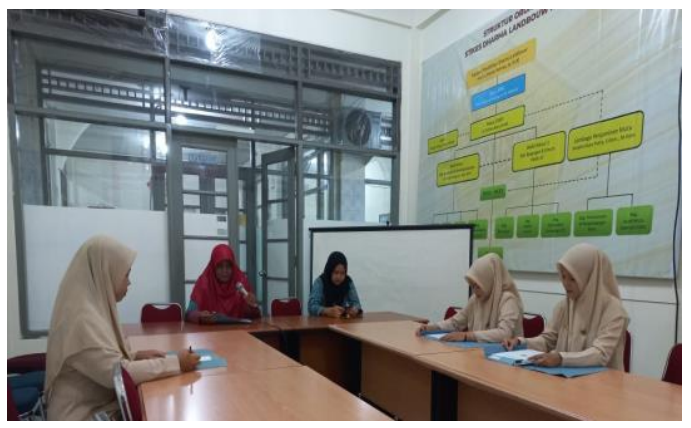

Gambar 3. Persiapan Pelaksanaan PKM

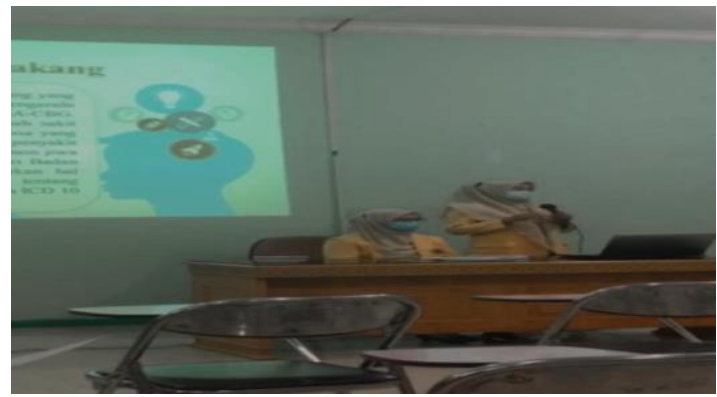

Gambar 4. Penyampaian Materi

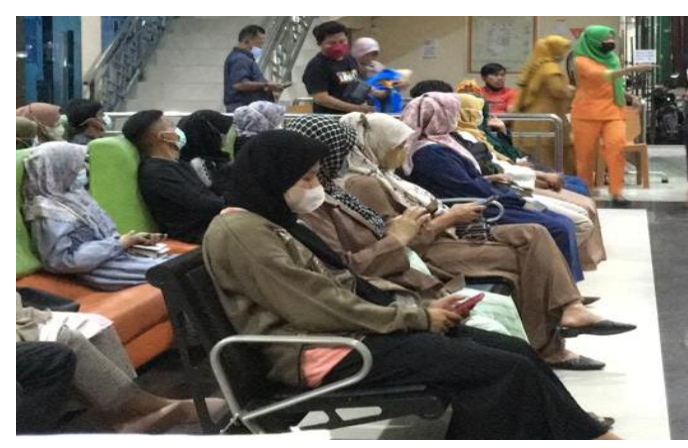

Gambar 5. Peserta Kegiatan

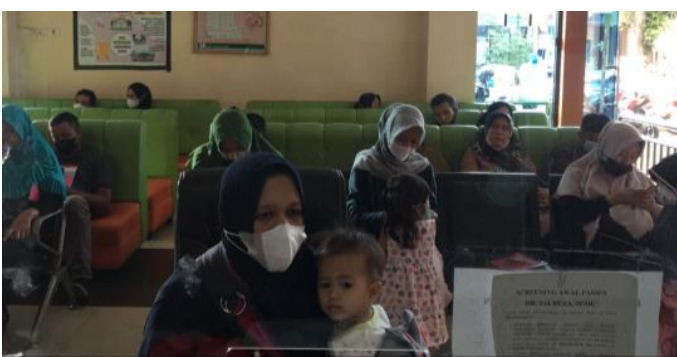

Gambar 6. Peserta Kegiatan

4. Tahap Post interaksi.

Tahap ini adalah Kegiatan terakhir yang dilakukan adalah evaluasi yang meliputi evaluasi struktur, Proses dan hasil. Keberhasilan kegiatan dengan responden yaitu pasien yang datang ke puskesmas. Berdasarkan hasil observasi yang dilakukan Hasil evaluasi dilakukan melalui tanya jawab pengabdi dengan peserta, yang menunjukkan bahwa kegiatan Sosialisasi pentingnya Kartu Kunjugan Berobat dan pasien sudah paham bahwa pasien harus wajib membawa kartu tersebut.

Kemampuan penyaji menyampaikan materi dengan bantuan media yang menarik sehingga memudahkan pasien untuk memahami isi yang disampaikan. Pemilihan alat dan bahan yang sederhana seperti leaflet dan brosur di 
1275 Sosialisasi Pentingnya Kartu Kunjungan Berobat Pasien di Puskesmas Ulak Karang Padang - Dewi Mardiawati, Berly Nisa Srimayarti, Linda Handayuni, Dian Sari, Hendra Nusa Putra, Annisa Septina Fariza, Annisa Zakia, Aqia Defira Dinda

DOI: https://doi.org/10.31004/abdidas.v2i6.345

sekitar peserta sehingga materi mudah di pahami oleh pasien.

\section{SIMPULAN}

Kesimpulan yang dapat diperoleh dari pelaksanaan pengabdian masyarakat dengan tema "Sosialisasi Pentingnya Kartu Kunjungan Berobat Pasien di Puskesmas Ulak Karang Padang":

1. Kegiatan soasilisasi pentingnya kartu kunjungan/kartu identitas berobat merupakan indikator mutu pelayanan yang dilakukan di Puskesmas Ulak Karang Padang berjalan dengan lancar.

2. Peserta dalam pelaksanaan terlihat bersemangat dan aktif selama mengikuti kegiatan sosialisasi.

3. Keberhasilan sosialisasi dipengaruhi oleh kemampuan penyaji menyampaikan materi dengan bantuan media yang menarik.

4. Pemilihan alat dan bahan yang sederhana seperti leaflet dan brosur juga harus diperhatikan atau disiap agar mempermudah pasien dalam memahami materi tersebut.

\section{DAFTAR PUSTAKA}

Anton, S. Kartu Berobat Bukan Hanya Sekedar Kartu - Anton Susanto Mmr Umy (2018).

Berly Nisa Srimayarti, K. N. S. (2019). Prototyping Personal Health Records For Type 2 Diabetes Mellitus Prevention. Indian Journal of Public Health Research \& Development, 10(11). Retrieved From Https://Web.B.Ebscohost.Com/Abstract?Dire $\mathrm{ct}=$ True $\&$ Profile $=$ Ehost $\&$ Scope $=$ Site $\&$ Autht ype $=$ Crawler $\& \mathrm{~J} r n l=09760245 \& A n=1412741$ $53 \& \mathrm{H}=\mathrm{Qicm} \% 2$ bleqraoahvejq9uff7zywrqh\% $2 \mathrm{~b} 7 \mathrm{~m} \% 2$ bywbp0o $4 \mathrm{~d} \% 2 \mathrm{fmu} 9 \mathrm{f} \% 2 \mathrm{bqghfc} 3 \mathrm{o} \%$ 2b5kzc72hi3x3ehqx\%2f\%2bdt9zhqau $\% 2 \mathrm{fc} \%$ 2 bgnvw\%3d\%3d\&Crl=C \&Resultns=Admin
webauth\&Resultlocal=Errcrlnotauth\&Crlhas hurl=Login.Aspx\%3fdirect\%3dtrue\%26profil e\%3dehost\%26scope\%3dsite\%26authtype\%3 dcrawler\%26jrnl\%3d09760245\%26an\%3d14 1274153

Budi, S. (2011). Manajemen Unit Kerja Rekam Medis. Yogjakarta: Quantum Sinergi Media.

Bustami. (2011). Penjaminan Mutu Pelayanan Kesehatan Dan Akseptabilitasnya. Erlangga.

Departemen Kesehatan Republik Indonesia. Pedoman Penyelenggaraan Rekam Medis (2006). Jakarta.

Devid Leonard, A. N. (2017). Analisis Desain Formulir Kartu Rawat Jalan Berdasarkan Metode Performance Information Economic Control Efficiency Service (Pieces) Di Puskesmas Rawang Padang Tahun 2017. Menara Ilmu, Xi(78), 133-146. Retrieved From

Https://Jurnal.Umsb.Ac.Id/Index.Php/Menara ilmu/Article/View/421/364

Harjani, A. S. W. (2020). Penerapan Kartu Indentitas Berobat ( Kib ) Dalam Pelaksanaan Family Numbering System. Prosiding: Seminar Manajemen Informasi Kesehatan Nasional Dan Call For Paper " $E$ Health Dalam Pelayanan Kesehatan," 10 14.

Kementerian Republik Indonesia. Peraturan Menteri Kesehatan Republik Indonesia No. 269/ Menkes/ Iii/ 2008 Tentang Rekam Medis (2008). Jakarta.

Permenkes Ri. Nomor 75 Tahun 2014 Tentang Pusat Kesehatan Masyarakat (2014). Indonesia. Retrieved From Http://Hukor.Kemkes.Go.Id/Uploads/Produk _Hukum/Pmk No. 75 Ttg Puskesmas.Pdf

Sudra, R. (2013). Rekam Medis Edisi 2. Tangerang Selatan: Universitas Terbuka. 